\title{
Optimization of Electrical Discharge Machining Process Parameters using SCM420 low alloy steel by Response Surface Methodology
}

\author{
K.S Morankar ${ }^{1}$, R.D.Shelke ${ }^{2}$ \\ ${ }^{I}$ (Department of Mechanical Engineering, Everest College of Engineering and Technology, Aurangabad, \\ Maharashtra, India) \\ ${ }_{2}^{2}$ (Department of Mechanical Engineering, Everest College of Engineering and Technology, Aurangabad, \\ Maharashtra, India)
}

\begin{abstract}
Electrical discharge machining is a nonconventional machining process which enables machining of complex and intricate shapes, hard materials that are precise and difficult to machine such as heat treated tool steels, composites, super alloys, ceramics, carbides, heat resistant steels etc. The process involves spark erosion in the presence of dielectric fluid. In this work SCM 420low alloy steel is the material used for the machining purpose with electrolyte copper as tool. This work investigates effect of process parameters peak current $\left(I_{P}\right)$, Pulse on time $\left(T_{\text {on }}\right)$ and gap voltage $(\mathrm{Vg})$ on Material removal rate $(M R R)$ and surface roughness $\left(R_{a}\right)$. Response surface methodology is used for experimental design. The suggested model can be used in the different manufacturing firms by selecting right combination of process parameters to achieve optimal values of output responses.
\end{abstract}

Keywords: Electrical discharge machining, Material removal rate, Peak current, Response surface methodology, Surface roughness

\section{Introduction}

Electrical discharge machining is one of the most widely used nonconventional processes. The surface of material is cut due to spark erosion by means of a formed electrode tool. This sparks occur across a small gap between tool and work surface. The EDM process is carried out in the presence of a dielectric fluid which creates a path for each spark as the fluid becomes ionized in the gap. The sparks are generated by a power supply connected to the work piece and the tool. The discharge occurs at the location where the two surfaces are close to each other. The dielectric fluid ionizes at this location. The work surface is suddenly melted and removed due to generation of extreme high temperature due to which material erosion takes place. The flowing dielectric then flushes away the removed particles of material [1]. SCM 420 is low alloy steel which has high fatigue strength is used to make all kinds of fasteners; high pressure pipe and more advanced carburized parts, such as gear, shaft, crankpin etc.

Recently several research works related to different aspects of EDM on different work piece and tool material have been done. It is noticed that Milan Kumar Das et. al. observed the effect of process parameters on MRR and $\mathrm{R}_{\mathrm{a}}$. Electrical discharge machining of EN31 tool steel was done using artificial bee colony (ABC) algorithm. Response surface methodology was used for experimental design [2]. Mehdi Hourmand et. al. used a copper electrode and oil based dielectric fluid mixed with aluminum powder. Response surface methodology was used to analyze EDM. They illustrated the effect of input variables on MRR, EWR and microstructure changes. Conclusion was made that current and pulse on time is the most significant factors on MRR [3]. S. Gopalakannan et. al. studied the effect of process variables on MRR, EW and $\mathrm{R}_{\mathrm{a}}$. The newly engineered metal matrix composite of aluminium 7075 reinforced with $10 \mathrm{wt} \%$ of B4C particles were prepared by stir casting method. Experiments were carried out by response surface methodology. They found two main significant factors that affect the MRR and $\mathrm{R}_{\mathrm{a}}$ are pulse current and pulse on time [4].The influence of operating parameters on the EDM of WPS DIN 1.2379/AISI D2 tool steel using the copper electrode material was studied by S. B. Chikalthankar, et. al. Design of experiment was conducted with L9 orthogonal array and Multi- objective Optimization was carried out with the help of Response surface methodology to optimize both the responses. [5]. The investigation for the Effect of the process parameters on MRR was done by Md. Ashikur Rahman Khan. Analysis and modeling was carried out using design of experiment and response surface methodology. They concluded that, high ampere combined with short off time and low servo voltage yield maximum MRR [6]. The feasibility of machining Ti6Al4V with a bundled electrode was studied by Lin Gu, LeiLi et. al. and its effect on EDM performance was compared experimentally using a solid die-sinking electrode. They observed that, compared with a solid die-sinking electrode, bundled electrodes can endure a much higher peak current which results in higher MRR and a lower TWR [7]. Ko-Ta Chiang has studied the effects of machining 
parameters on the performance characteristics in the EDM process of Al2O3+TiC mixed ceramic. Mathematical models were developed using the response surface methodology to explain the influences of machining parameters [8]. Mr. Kurri Rohan Ramesh and Jagtap Shrikant Tukaram have studied the effect of process parameters on $\mathrm{R}_{\mathrm{a}}$. The work piece material was alloy steel (EN-31). They prepared mathematical models using the response surface methodology (RSM) to correlate dominant machining parameters [9]. Optimization of MRR and TWR was done on EDM by Suresh Kumar Gurjar and Rajeev Kumar by using Taguchi and ANOVA. They attempted for finding feasibility of machining die steel H13 work piece using circular copper electrode and dielectric flushing. They observed that current have the statistical significance on MRR whereas TWR is influenced by current, feed and pulse on time [10]. Experiments were conducted for three different work piece materials to find the effect of work piece material variation by P. Sahoo et. al. by using RSM. Influence of machining parameters was studied on the quality of surface produced in EDM. Five roughness parameters, such as centre line average roughness, root mean square roughness; skewness, kurtosis and mean line peak spacing have been considered. They found that, pulse current has the maximum influence on the roughness parameters [11].There is no research found addressing the effects of EDM parameters (peak current, pulse on time and gap voltage) on SCM420 low alloy steel material. High MRR and low surface roughness are important in the roughing step of the EDM process. Therefore, developing a mathematical model and simultaneously evaluating the optimized machining parameters for MRR and $\mathrm{R}_{\mathrm{a}}$ during the EDM process of SCM420 low alloy steel material are some of the goals of the current research. Another aim is to observe the effects of EDM parameters on the output responses MRR and $\mathrm{R}_{\mathrm{a}}$. For this purpose MINITAB's Central Composite experimental design of response surface methodology is used.

\section{Experimental set up}

The experiments were carried out on an Electrapuls PS 50 ZNC electrical discharge machine on round bars of SCM420 material ( 55 to $57 \mathrm{HRC}$ ) with diameter $38 \mathrm{~mm}$ with Electrolyte copper as electrode (tool of 20 $\mathrm{mm}$ diameter). The polarity of the electrode was positive and EDM oil (mixture of paraffin, kerosene and demonized water) was used as dielectric fluid. For experimentation purpose and for each run same tool was used and a circular cavity of $20 \mathrm{~mm}$ diameter and $2 \mathrm{~mm}$ depth was made centrally on face of each work piece by spark erosion on EDM. Pictorial View of experimental set-up is shown in the Fig. 2.1.

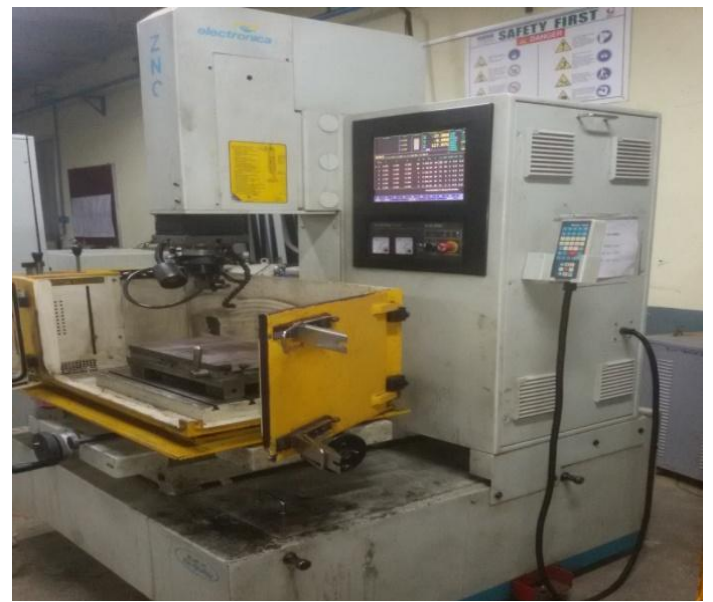

Fig. 2.1 Pictorial View of Electrapuls PS 50 ZNC electrical discharge machine

\subsection{Work piece material}

SCM420 low alloy steel is used as work piece material. ( $\Phi 38 \mathrm{~mm} \mathrm{X} 40 \mathrm{~mm})$ The chemical composition of material is shown in Table 2.1.1

Table 2.1.1 Chemical composition

\begin{tabular}{|c|c|c|}
\hline Element & Min & Max \\
\hline Carbon, $\mathrm{C}$ & 0.18 & 0.23 \\
\hline Manganese, Mn & 0.60 & 0.90 \\
\hline Silicon, Si & 0.15 & 0.35 \\
\hline Nickel, Ni & 0.00 & 0.25 \\
\hline Molybdenum, Mo & 0.15 & 0.25 \\
\hline Chromium, $\mathrm{Cr}$ & 0.90 & 1.20 \\
\hline Vanadium, V & - & - \\
\hline $\mathrm{Cu}$ & 0.00 & 0.30 \\
\hline Sulfur, $\mathrm{S}$ & 0.00 & 0.030 \\
\hline Phosphorous, $\mathrm{P}$ & 0.00 & 0.030 \\
\hline
\end{tabular}


The mechanical properties of material are shown in Table 2.1.1

Table 2.1.2 Mechanical Properties

\begin{tabular}{|l|l|l|}
\hline Properties & Value & Unit \\
\hline Young's modulus & $200000-200000$ & $\mathrm{MPa}$ \\
\hline Tensile strength & $650-880$ & $\mathrm{MPa}$ \\
\hline Elongation & 41876 & $\%$ \\
\hline Fatigue & $275-275$ & $\mathrm{MPa}$ \\
\hline Yield strength & $350-550$ & $\mathrm{MPa}$ \\
\hline
\end{tabular}

\subsection{Levels of process parameters}

The process parameters chosen for the present study are peak current (Amperes), pulse on time ( $\mu$ secs) and gap voltage $(\mathrm{Vg})$. The selection of the values of the variables is limited by the capacity of the machine used in the experimentation as well as recommended combinations depending on work piece and tool material. Process parameters and their levels are shown in Table 2.1.3

Table 2.1.3 Process parameters and their levels (3 levels each for 3 factors)

\begin{tabular}{|l|l|l|l|}
\hline \multirow{2}{*}{ Process Parameter } & Level & Migh (+1) \\
\cline { 2 - 4 } & Low (-1) & Medium (0) & 22 \\
\hline Peak current (Amperes) & 10 & 15 & 750 \\
\hline Pulse on time ( $\mu$ secs) & 400 & 500 & 32 \\
\hline Voltage gap (Volts) & 25 & 30 & \\
\hline
\end{tabular}

\subsection{Experimental Result}

\section{Results and discussion}

In this chapter, result through experimental work is recorded, as shown in table 3.1. Response surface methodology is used for design of experiments. Experimental data obtained for Surface Roughness $\left(\mathrm{R}_{\mathrm{a}}\right)$ and Material Removal Rate (MRR) is analyzed and Mathematical modeling is done for both output responses.

Table 3.1 Experimental result

\begin{tabular}{|l|l|l|l|l|l|}
\hline Exp. run & $\begin{array}{l}\mathbf{I}_{\mathbf{p}} \\
(\text { Amp) }\end{array}$ & $\begin{array}{l}\mathbf{T}_{\text {on }} \\
(\mathbf{s e c})\end{array}$ & $\begin{array}{l}\mathbf{V}_{\mathbf{g}} \\
(\mathbf{v o l t s})\end{array}$ & $\begin{array}{l}\mathbf{M R R} \\
\left(\mathbf{m m}^{\mathbf{3}} / \mathbf{s e c s}\right)\end{array}$ & $\begin{array}{l}\mathbf{R a} \\
(\boldsymbol{\mu m})\end{array}$ \\
\hline 1 & -1 & -1 & -1 & 2.5 & 5.1 \\
\hline 2 & +1 & -1 & -1 & 4.1 & 5.2 \\
\hline 3 & -1 & +1 & -1 & 2.3 & 5.9 \\
\hline 4 & +1 & +1 & -1 & 5.2 & 6.2 \\
\hline 5 & -1 & -1 & +1 & 2.8 & 5.4 \\
\hline 6 & +1 & -1 & +1 & 4.1 & 6.9 \\
\hline 7 & -1 & +1 & +1 & 3 & 5.5 \\
\hline 8 & +1 & +1 & +1 & 4.9 & 6.9 \\
\hline 9 & -1 & 0 & 0 & 4 & 4.8 \\
\hline 10 & +1 & 0 & 0 & 5.1 & 7 \\
\hline 11 & 0 & -1 & 0 & 4 & 6.2 \\
\hline 12 & 0 & +1 & 0 & 3.2 & 6.5 \\
\hline 13 & 0 & 0 & -1 & 3.3 & 5.5 \\
\hline 14 & 0 & 0 & +1 & 3.2 & 6.7 \\
\hline 15 & 0 & 0 & 0 & 2.7 & 6.4 \\
\hline 16 & 0 & 0 & 0 & 2.9 & 5.8 \\
\hline 17 & 0 & 0 & 0 & 3 & 7 \\
\hline 18 & 0 & 0 & 0 & 3.1 & 6.8 \\
\hline 19 & 0 & 0 & 0 & 3.2 & 6 \\
\hline 20 & 0 & 0 & 0 & 3.3 & 6.4 \\
\hline
\end{tabular}

\subsection{Discussion}

Comparing the $p$-value to a commonly used $\alpha$-level $=0.05$, it is found that if the $p$-value is less than or equal to $\alpha$, it can be concluded that the effect is significant. This clearly indicates that $\mathrm{R}_{\mathrm{a}}$ and MRR are greatly influenced by the peak current followed by pulse on time and gap voltage. It can be observed from Graph 3.2.1 that peak current has a huge impact on roughness value $R_{a}$. Graph shows peak current, pulse on time and gap voltage at low level gives low $R_{a}$ value and peak current at high level gives high $R_{a}$ value. The graph shows that increase in peak current and pulse on time results in increase of $R_{a}$ value. 


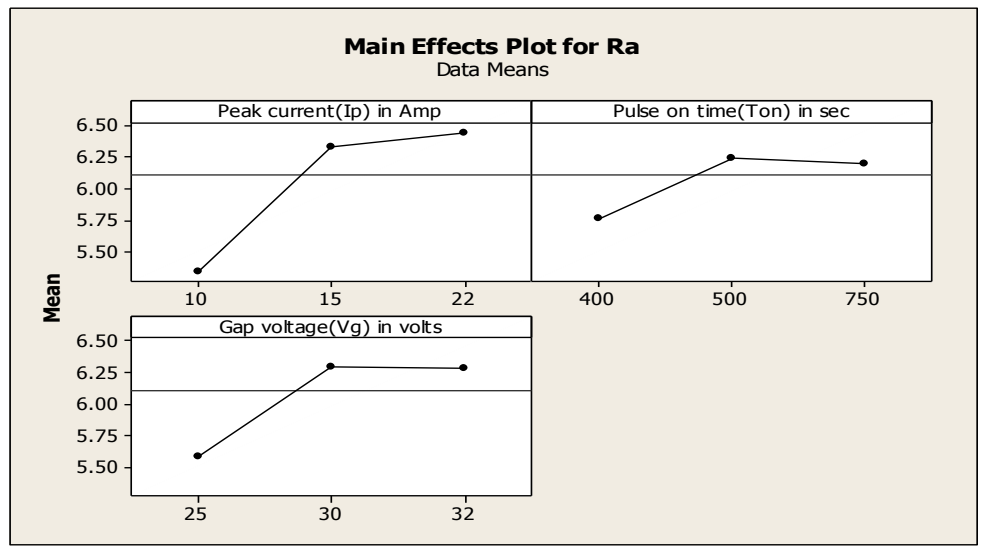

Graph 3.2.1 Main effects plot for $\mathrm{R}_{\mathrm{a}}$

Based on the analysis of residual plot for $\mathrm{R}_{\mathrm{a}}$ as shown in graph 3.2.2 the residuals appear to be evenly scattered about zero. Therefore it shows that constant variation is observed between residuals and fitted values and no evidence of non constant variance, missing terms, outliers, or influential points exist. Constant variance indicates that the model developed is adequate.

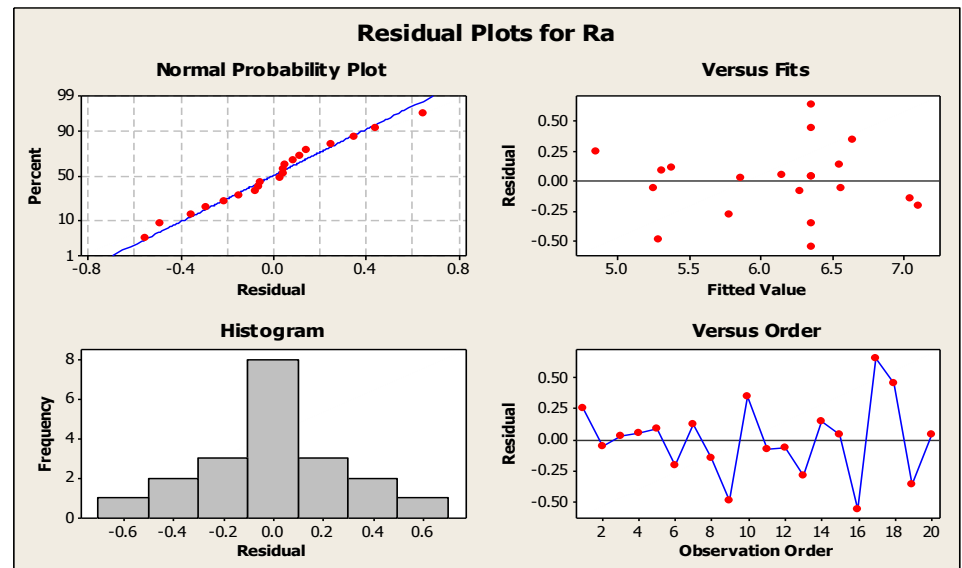

Graph 3.2.2 Residual plots for $\mathrm{R}_{\mathrm{a}}$

Graph 3.2.3 shows that peak current is the most significant parameter for MRR. Whereas MRR increases at higher level of pulse on time. Gap voltage has no significant effect on MRR.

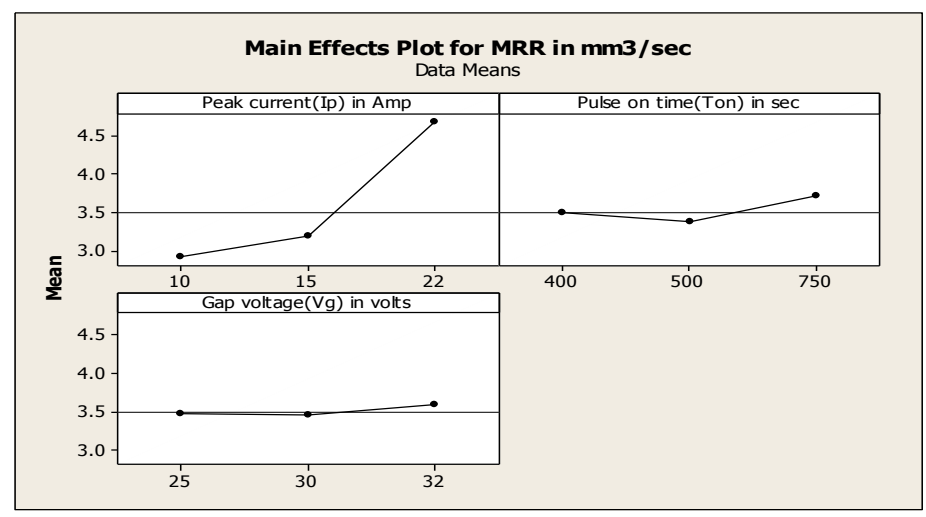

Graph 3.2.3 Main effects plot for MRR

For MRR data, the residuals generally appear to follow the straight line. Therefore, the given design is well balanced and no evidence of non normality, skewness, outliers, or unidentified variables exists. Graph 3.2.4 shows that the residuals generally fall on a straight line, implying that the errors are normally distributed. This could be concluded that the models proposed for the MRR are adequate, and there is no reason to suspect any violation of the independence or constant variance assumption. 


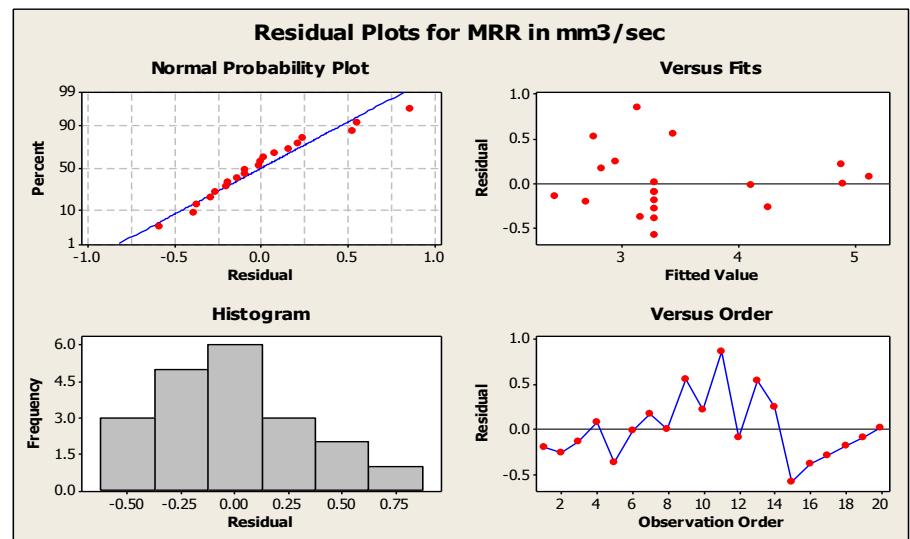

Graph 3.2.4 Residual plots for MRR

\section{Conclusions}

In present work, experimental investigation has been done for EDM process of SCM 420 low alloy steel ( $\Phi 38 \mathrm{~mm}$ X 40mm) (Hardened to $57 \mathrm{HRc}$ ). Response surface methodology (RSM) has been utilized to investigate the influence of three important parameters - peak current (Amperes), pulse on time ( $\mu$ secs) and gap voltage $(\mathrm{Vg})$ on two responses namely Surface Roughness $\left(R_{a}\right)$ and Material Removal Rate (MRR). The analysis of experimental work is performed using MINITAB 16 statistical software and optimum values are calculated and confirmation tests are done. The important conclusions from the present research work are summarized as follows.

a. Optimum values for process parameters are found to be peak current (22Amperes), pulse on time (460 $\mu$ secs) and gap voltage ( 25 volts).

b. From statistical analysis, it is clear that pulse on time have significant effects on surface roughness and MRR values. Whereas peak current is most significant parameter for $R_{a}$.

c. When peak current and pulse on time is increased the MRR is increased. Gap voltage has no influence on MRR.

d. Value of $\mathrm{R}_{\mathrm{a}}$ is decreases when peak current, pulse on time and gap voltage decreases.

e. Confirmation test error is less than $5 \%$ which indicates the validation of the predicted models.

\section{References}

[1] Mikell P. Groover, Fundamentals of modern manufacturing (John Wiley and Sons Inc,2010)

[2] Milan Kumar Das, Kaushik Kumar, Tapan Kr. Barman and Prasanta Sahoo, "Application of Artificial bee Colony Algorithm for Optimization of MRR and Surface Roughness in EDM of EN31 tool steel", Elsevier, Procedia Materials Science, 741 - 751, May 2014.

[3] Mehdi Hourmand, Saeed Farahany, Ahmed A. D. Sarhan and Mohd Yusof Noordin, "Investigating the Electrical Discharge Machining (EDM) Parameter effects on Al-Mg2Si Metal Matrix Composite (MMC) for high Material Removal Rate (MRR) and less EWR-RSM approach", Springer, International Journal of Advanced Manufacturing and Technology, October 2014.

[4] S. Gopalakannan, T. Sentjhilvelan and S. Ranganathan, "Modeling and Optimization of EDM Process Parameters on Machining of Al 7070-B ${ }_{4}$ C using RSM”, Procedia Engineering, 38, 685-690, 2012.

[5] S. B. Chikalthankar, V. M. Nandedkar and S .V. Borde, "Experimental Investigations of EDM Parameters." International Journal of Engineering Research and Development, 7(5), 31-34, June 2013.

[6] Md. Ashikur Rahman Khan, M .M. Rahman, K. Kadirgama and A. R. Ismail, "RSM Model to evaluate Material Removal rate in EDM of Ti-5Al-2.5Sn using Graphite Electrode.", Materials Science and Engineering, 36, 1-9, 2012

[7] Lin Gu, LeiLi, Wansheng Zhao and K. P. Rajurkar, "Electrical Discharge Machining of Ti6Al4V with a bundled Electrode", Elsevier, International Journal of Machine Tools \& Manufacture, 53, 100-106, 2012.

[8] Ko Ta Chiang, "Modeling and analysis of the effects of Machining Parameters on the Performance characteristics in the EDM process of A12O3+TiC mixed Ceramic.", International Journal of Advanced Manufacturing and Technology, 37, 523-533, 2008.

[9] Kurri Rohan Ramesh, Jagtap Shrikant Tukaram, "The effects of Machining Parameters on Surface Roughness of Material EN-31 in EDM using Copper Electrode.”, International Journal of innovations in Engineering Research and Technology, 2(9), 1-8, September 2015.

[10] Suresh Kumar Gurjar and Rajeev Kumar, "Optimization of MRR and TWR on EDM by using Taghuchi's Method and ANOVA Die Steel H13.”, International journal for Innovative Research in Science and Technology, 2(3), 22-28, August 2015.

[11] P. Sahoo, B .C. Routara and Bandyopadhyay, "Roughness modeling and optimization in EDM using Response Surface Method for different Work piece Materials.” International Journal of Machining and Machinability of Materials, 5, 321-346, 2009.

[12] Nibu Mathew, Dinesh Kumar, Naveen Beri and Anil Kumar, "Study of Material Removal Rate of different Tool Materials during EDM OF H11 Steel at Reverse polarity", International Journal of Advanced Engineering Technology, V(II), pp. 25-30, April-June, 2014. 